\title{
Effects of mixed micro and nano silica particles on the dynamic compressive performances of epoxy adhesive
}

\author{
Yohanes $^{1}\left[0\right.$ and Yasuhisa Sekiguchi ${ }^{*}$
}

*Correspondence:
sekiguch@hiroshima-u.ac.jp
2 Institute of Engineering,
Hiroshima University,
1-4-1 Kagamiyama,
Higashi-Hiroshima-shi,
Hiroshima 739-8527, Japan
Full list of author information
is available at the end of the
article

${ }^{*}$ Correspondence: sekiguch@hiroshima-u.ac.jp Hiroshima University,

1-4-1 Kagamiyama,

Higashi-Hiroshima-shi, Hiroshima 739-8527, Japan

\begin{abstract}
Effects of mixed micro and nano silica particles on the dynamic stiffness, stress transmissibility, and energy absorption of the epoxy composite were investigated using the split Hopkinson pressure bars. It was found that the dynamic stiffness significantly increased with silica weight fraction regardless of its sizes and composition ratio. However, the effect became less significant as the temperature approached $T_{g}$. It was also found that mixed micro and nano silica particles decreased both the epoxy dynamic stiffness and the stress transmissibility, and increased the energy absorption. The optimum composition ratio was found to maximize the energy absorption while maintaining high stiffness performance of epoxy. The results obtained in the present work can be used to design the performance of epoxy/silica adhesive for appropriate applications.
\end{abstract}

Keywords: Epoxy adhesive, Silica filler, Dynamic stiffness, Energy absorption, Split Hopkinson pressure bar

\section{Background}

Epoxy is widely used both as adhesives and composites in industrial and structural applications due to its superiority in strength to weight ratio. Understanding the stiffness and damping behaviors of epoxy at various strain rate is critical for design and analysis purposes. Such behaviors are required to estimate the response of structures subjected to dynamic loads such as impact and shock. The stiffness and damping of epoxy composite depend on the inherent characteristics of its constituent materials and their interactions. Silica particles are commonly used to enhance the epoxy stiffness due to their high modulus and strong adhesion with the epoxy matrix. Such adhesion restricts molecular mobility and deformation of the epoxy matrix at the interface area. The strengthen interface area improves the load transfer and the stiffness of epoxy/silica. High content and reduced size of silica particles enlarge the interface area. Nano silica is a superior epoxy stiffener compared with micro silica, which extends interface area and avoids stress due to its smaller size [1-7].

Nano silica particles must be well-dispersed in the epoxy matrix to improve the stiffness of epoxy [3]. However, without any surface modification, nano silica particles tend to aggregate or agglomerate, increase the epoxy viscosity, and have difficulties in

(c) The Author(s) 2017. This article is distributed under the terms of the Creative Commons Attribution 4.0 International License (http://creativecommons.org/licenses/by/4.0/), which permits unrestricted use, distribution, and reproduction in any medium, provided you give appropriate credit to the original author(s) and the source, provide a link to the Creative Commons license, and indicate if changes were made. 
the mixing process $[8,9]$. Mixing nano silica and larger particles, such as micro silica, prevents such agglomeration. However, investigation on the effects of mixed micro and nano silica particles on the epoxy stiffness is very limited.

Effect of two sizes silica particles on the epoxy stiffening depends on its size ratio. Kwon et al. [10] and Adachi et al. [11] using relatively small size ratio of silica fillers (i.e., 1.56 and $0.24 \mu \mathrm{m}$ in diameters), have reported that the composition ratio slightly affects both bending and static tensile stiffness. They have also found that the epoxy stiffness strongly depends on the weight fraction of the silica particles. More recently, using larger size ratio (i.e., $42 \mu \mathrm{m}$ and $23,74,174 \mathrm{~nm}$ in diameters), Dittanet et al. [12] have showed that the composition ratio of two sizes of silica particles significantly influences the tensile stiffness of epoxy. They have reported that introducing nano silica particle weakens the bonding strength between epoxy and micro silica, and thus affects the stiffness. It is important to note that the previous works studied the effect of two sizes of silica particles on the static stiffness of epoxy. Investigations on the effect of mixed micro and nano silica particles on the dynamic stiffness of epoxy have been paid a little attention to.

High strain rate loading and silica particles restrict the molecular mobility of the epoxy matrix and result in a stiffer dynamic response [13-18]. The weight fraction, size, and distribution of silica particles affect the epoxy dynamic stiffness. Reducing silica particles size into nanoscale increases the epoxy dynamic stiffness [13, 18-20]. In contrast, the molecular mobility increases with the temperature and reduces the dynamic stiffness [16]. Introducing silica particles restricts molecular mobility, and thus increase the dynamic stiffness. It is important to note that the epoxy/silica interactions at high strain are very complicated and have been paid only a little attention to. Therefore, the present research contribution is to fill such gap of knowledge and to provide experimental evidence for practical implementation. Such knowledge and evidence are necessary to design the dynamic performances of epoxy for appropriate applications.

The present research investigates the effects of mixed micro and nano silica particles on the dynamic stiffness, stress transmissibility, and energy absorption of epoxy. The investigation was carried out using split Hopkinson pressure bars at various temperatures.

\section{Methods}

Materials and specimen preparation

The specimens were composed of epoxy Scotch-Weld 1838, branded by $3 \mathrm{M}^{\mathrm{TM}}$ with glass transition temperature $\left(T_{g}\right)$ of $55^{\circ} \mathrm{C}$. Mixed micro and nano silica particles, without any surface treatment, were used to modify the epoxy stiffness. Micro and nano silica are 74 GPa of Young's Modulus, $17 \mu \mathrm{m}$ and $34 \mathrm{~nm}$ in diameters, and with 3.4 and $80 \mathrm{~m}^{2} \mathrm{~g}^{-1}$ in specific surface areas, respectively. The epoxy and silica were stirred until homogeneous using a planetary centrifugal mixer (Thinky AR-100). The degassing process was applied to remove bubbles from the mixture before poured it into the mold as shown in Fig. 1 and cured for $24 \mathrm{~h}$. The cylindrical specimen was $16 \mathrm{~mm}$ in diameter and ratio of thickness to diameter was 0.5 . Such dimensions were chosen to ensure full contact surface and to avoid the inertia effect during the measurements. The silica weight fractions were 5 and $10 \%$ and the composition ratio are listed in Table 1. 


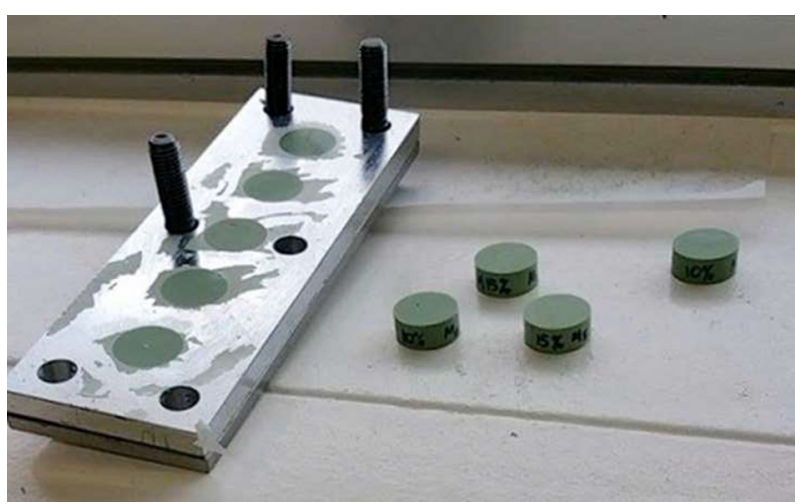

Fig. 1 Specimen and mold

Table 1 Composition ratio of silica micro and nanoparticle

\begin{tabular}{llc}
\hline Mixture ratio, $\boldsymbol{\Phi}_{S P}(\%)$ & \multicolumn{2}{l}{ Silica particle diameter } \\
\cline { 2 - 3 } & $\mathbf{3 4} \boldsymbol{\mu \mathbf { m } ( \% )}$ & $\mathbf{1 7} \mathbf{~ n m ~ ( \% )}$ \\
\hline 0 (Micro only) & 100 & 0 \\
25 & 75 & 25 \\
50 & 50 & 50 \\
75 & 25 & 75 \\
100 (Nano only) & 0 & 100 \\
\hline
\end{tabular}

\section{Experimental apparatus and calibration}

Figure 2 shows the split Hopkinson pressure bars (SHPB) apparatus and measurements instruments for data recording. A careful design of the SHPB complied with the onedimensional stress wave propagation assumption. All bars were stainless steel, $20 \mathrm{~mm}$ in diameter, Young's modulus of $209 \mathrm{GPa}$, the density of $8750 \mathrm{~kg} \mathrm{~m}^{-3}$, and Poisson ratio of 0.3. Both input and output pressure bars were identical of $2000 \mathrm{~mm}$ in length. A crowned striker bar of $300 \mathrm{~mm}$ in length generated the incident strain wave of $200 \mu \mathrm{s}$ at the input bar and $140 \pm 5 \mathrm{~s}^{-1}$ strain rate at the specimen. The crowned impact face was used to increase the rise time and modify the shape of the generated incident pulse.

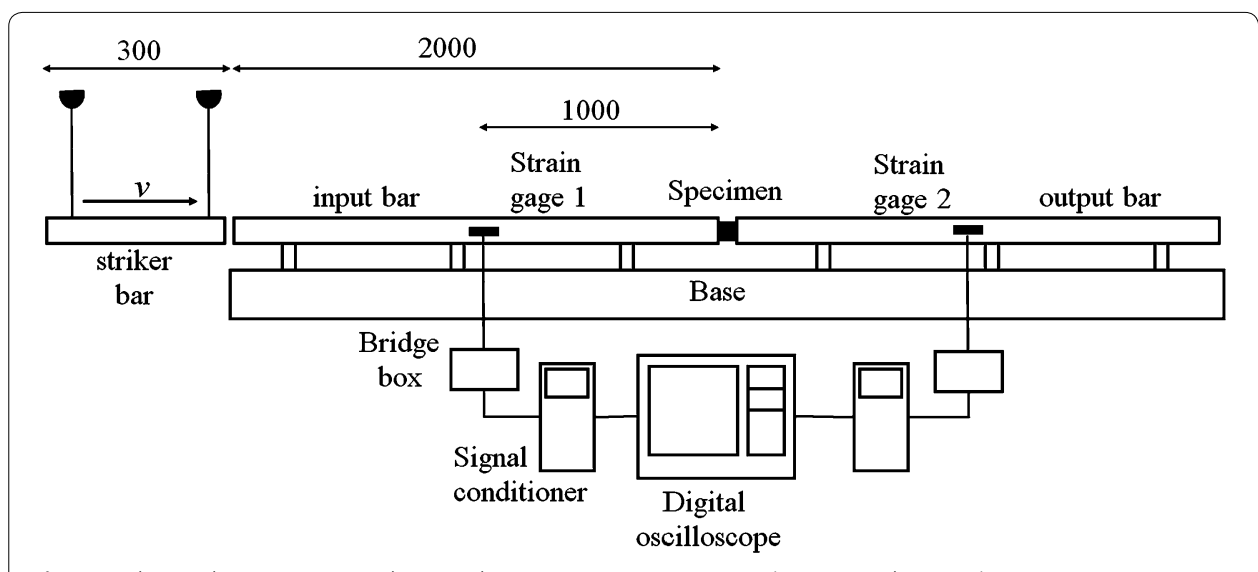

Fig. 2 Split Hopkinson pressure bars and measurement apparatus (units in milimeters) 
The incident wave transmitted to the output bar through the specimen and generated the transmitted wave. Some part of strain wave was reflected to the input bar due to the impedance mismatch. Strain gages measured the incident, reflected, and transmitted strain waves at the middle of pressure bars without overlap.

A calibration test was conducted on the pressure bars without a specimen to ensure the validity and accuracy of the obtained data. Considered as a single pressure bar, the interface of pressure bars was lubricated to minimize the friction. Figure 3 shows the identical of the incident and transmitted strain waves on the calibration test. The nonexisted reflected wave indicated that there was no impedance mismatch and the pressure bars were in good alignment. Therefore, the reflected wave in the specimen test shown in Fig. 4 was contributed only by specimen. Compressive forces on both sides of the specimen were also verified for dynamic equilibrium condition. Such state represented by the equivalent compressive forces at input bar $\left(P_{1}\right)$ and output bar $\left(P_{2}\right)$ interfaces as formulated in Eqs. 1 and 2,

$$
\begin{aligned}
& P_{1}=A_{B} E\left\{\varepsilon_{I}(t)+\varepsilon_{R}(t)\right\} \\
& P_{2}=A_{B} E \varepsilon_{T}(t)
\end{aligned}
$$

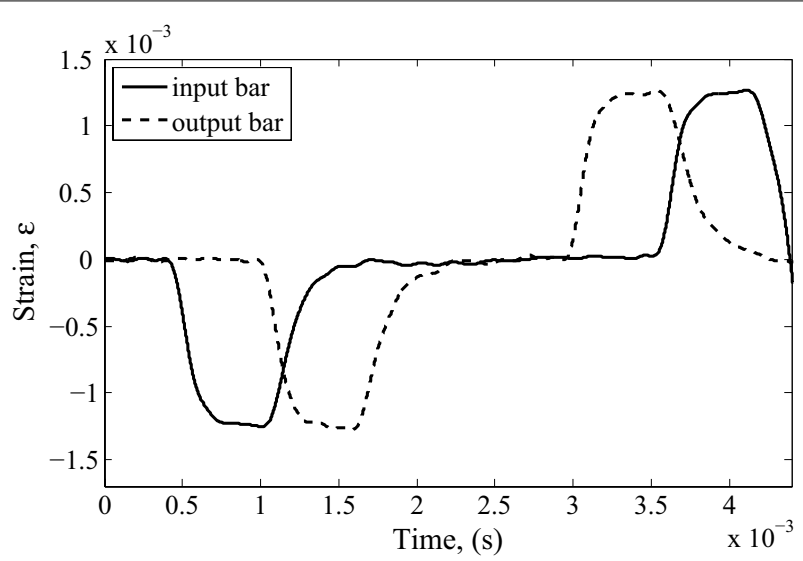

Fig. 3 Alignment calibration of SHPB

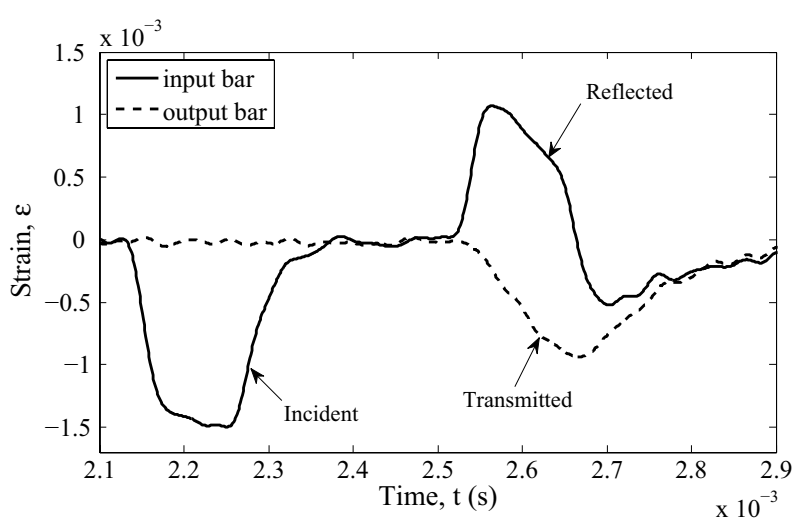

Fig. 4 Measured strain waves at pressure bars with specimen 
where $A_{B}$ is the cross-sectional area of the pressure bars, $E$ is Young's modulus of the bars, $\varepsilon_{I}, \varepsilon_{R}$, and $\varepsilon_{T}$ are the incident, reflected, and transmitted waves, respectively. The dynamic equilibrium in the measurement was confirmed by the similarity and coincidence of compressive forces as shown in Fig. 5. Therefore, the effect of friction on the SHPB system used in the present experiments can be ignored and the accuracy of the obtained data is verified.

\section{Stress-strain characteristic and stiffness estimation}

Since the measurement condition had been verified for its validity and accuracy, the strain rate history and stress-strain curves can be obtained from the measured strain waves using the following equations:

$$
\begin{aligned}
& \sigma_{n}=E A_{B} / A_{s} \varepsilon_{T}(t) \\
& \dot{\varepsilon}_{n}=2 C_{0} / L_{s} \varepsilon_{R}(t) \\
& \varepsilon_{n}=2 C_{0} / L_{s} \int \varepsilon_{R}(t) d t
\end{aligned}
$$

where, $C_{0}$ is the elastic wave speed through the bars, $L_{S}$ is the specimen thickness, $A_{S}$ is the cross-sectional area of the specimen, and $t$ is time duration. Strain rate time history and stress-strain curves obtained from the calculation are shown in Figs. 6 and 7, respectively.

In the ideal measurement, the working strain rate should be constant during loading. However, such condition is practically difficult to obtain. In the present research, strain rate always changes during loading as shown in Fig. 6. However, constant strain rate occurred for a short time near its maximum point during the compressive loading. Therefore, in the present research, the strain rate was determined at its maximum point.

The dynamic stiffness of specimen was estimated from the slope of the stress-strain curve as shown in Fig. 7.

\section{Estimation of stress transmissibility and energy absorption}

In the used SHPB method, the strain during the specimen expansion cannot be obtained. Therefore, the following relationships are introduced in the measurement.

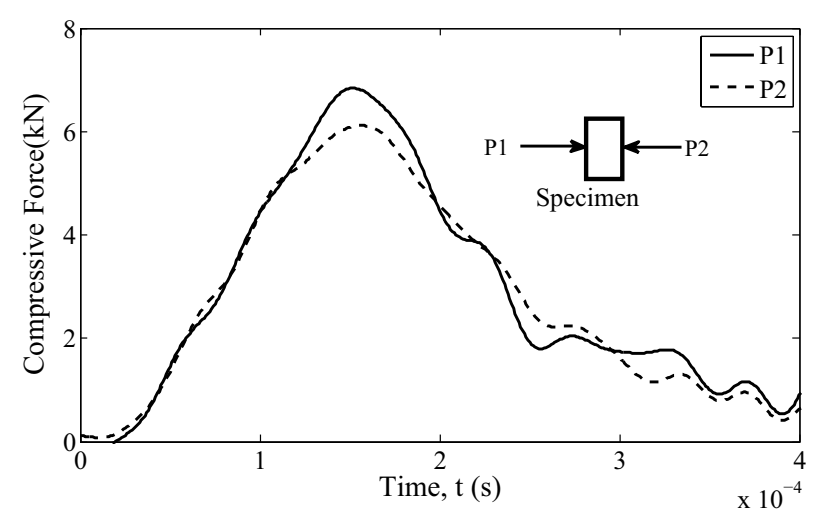

Fig. 5 Dynamic equilibrium verification at both sides of specimen 


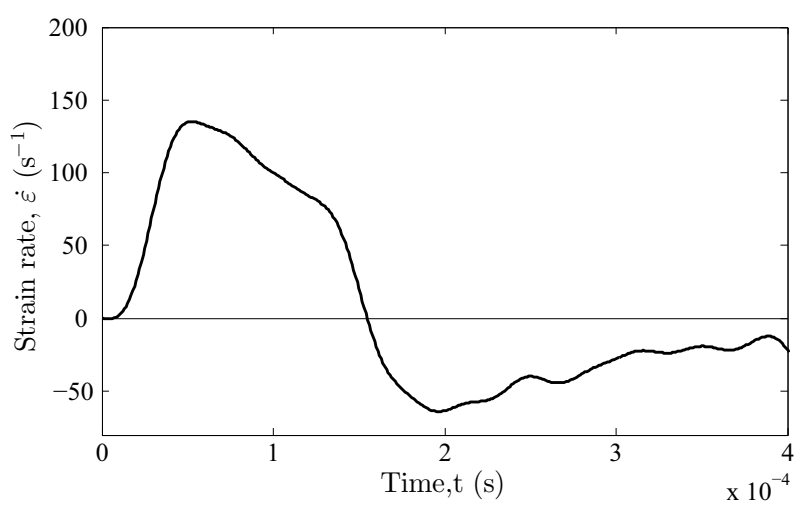

Fig. 6 Time history of the strain rate

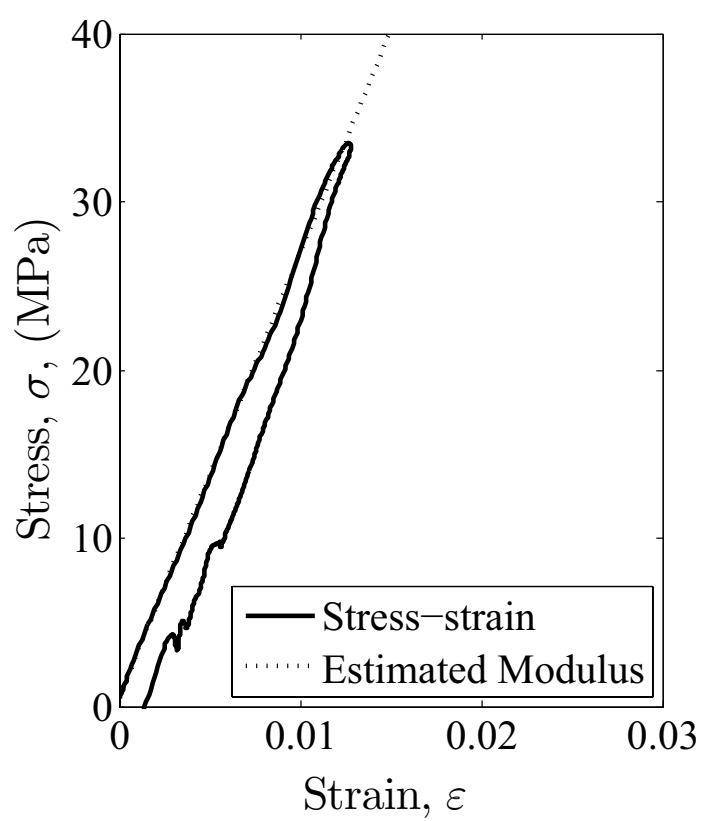

Fig. 7 Stress-strain curve and the estimated modulus

Stress transmissibility $\left(E_{\sigma}\right)$ defines the ability of the specimen to transmit stress from input bar to output bar during impact. Due to the identical of pressure bars, Eq. 6 formulates stress transmissibility as the ratio of the transmitted to the incident strain average. The strain averages are obtained by integrating strain waves respect to time as shown in Fig. 8.

Although strain averages do not quantify the energy dissipation in the specimen, the energy absorption performance ( $\left.E_{\text {Loss }}\right)$ still can be estimated by Eq. 7 because strain difference between input strain (incident) and output strain (reflected and transmitted) represents the energy dissipation in the specimen.

$$
E_{\sigma}=\int \varepsilon_{T} d t / \int \varepsilon_{I} d t \times 100 \%
$$




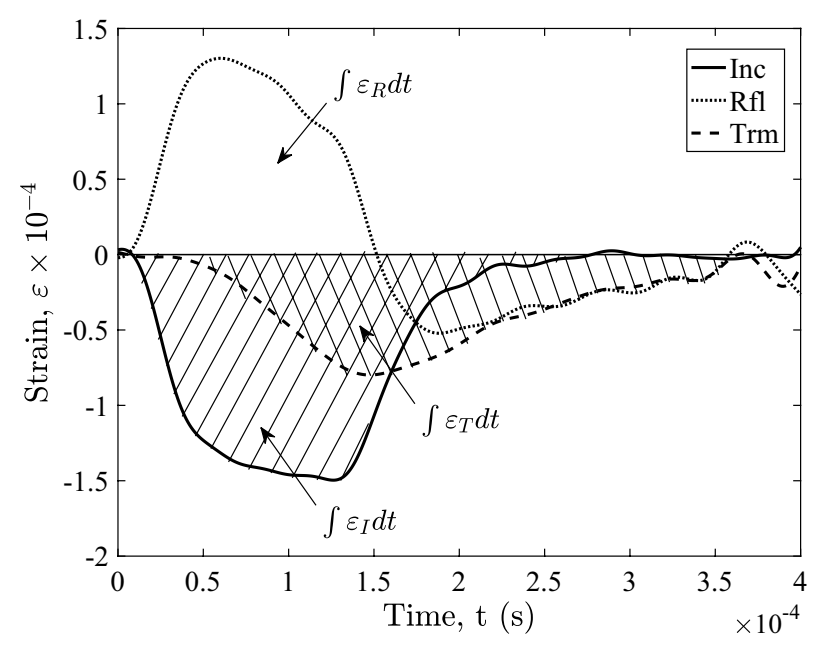

Fig. 8 The aligned pulses and strain averages

$$
E_{\text {Loss }}=\int\left(\varepsilon_{I}+\varepsilon_{R}-\varepsilon_{T}\right) d t / \int \varepsilon_{I} d t \times 100 \%
$$

\section{Results and discussion}

Effects of two sizes of silica particles on the dynamic stiffness of epoxy were investigated using the SHPB. The dynamic stiffness was estimated from the stress-strain curve obtained from the measured strain waves. The dynamic stiffness dependency on the composition ratio and the weight fraction of silica particles at different temperatures are presented in Fig. 9. The composition ratios, varied from pure micro silica $\left(\Phi_{S P}=0 \%\right)$ to pure nano silica $\left(\Phi_{S P}=100 \%\right)$, are represented by the horizontal axis. The dashed line represented the dynamic stiffness of the neat epoxy as a baseline. The stiffening effect of silica particles on the epoxy was measured by comparing the stiffness of epoxy/silica with the baseline.

Figure 9 highlights the stiffening effect on the epoxy due to the increase of silica weight fraction and composition ratio at the elevated temperature. The stiffening effect increased with the increase of silica weight fraction while it was not monotone with the composition ratio. However, such stiffening effect decreased when the temperature approached $T_{g}$. Therefore, the dependency of the stress transmissibility and the loss energy performance were evaluated at $\mathrm{T}=15^{\circ} \mathrm{C}$ as shown in Figs. 10 and 11, respectively. The effects of the composition ratio and the weight fraction of the silica particles on the dynamic stiffness, stress transmissibility, and loss energy performance will be discussed in the following subsections.

Deviations were found on the estimated dynamic stiffness, stress transmissibility, and loss energy performance. The deviations were mainly caused by the variation in the mixing process of specimens and the included noises in the measurement which distorted the shape of strain waves. The effect of such specimen variations on the deviations of data was minimized by using five samples for each variable in the weight fraction and composition ratio. The distorted strain waves influenced the obtained stress-strain curves and thus, resulted in the deviations of the estimated dynamic stiffness (Fig. 9). 


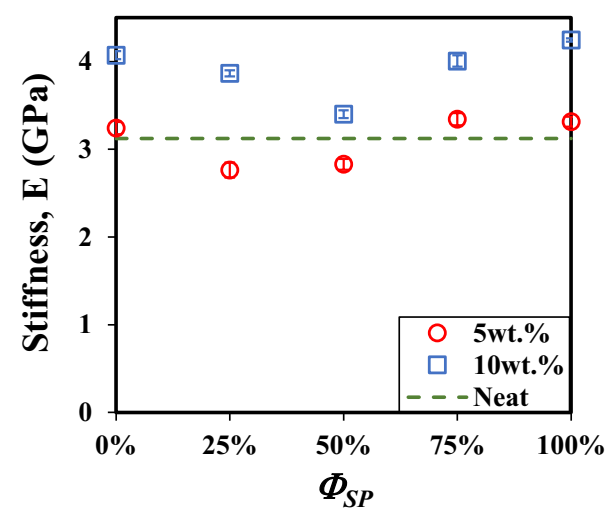

$\mathbf{a}$

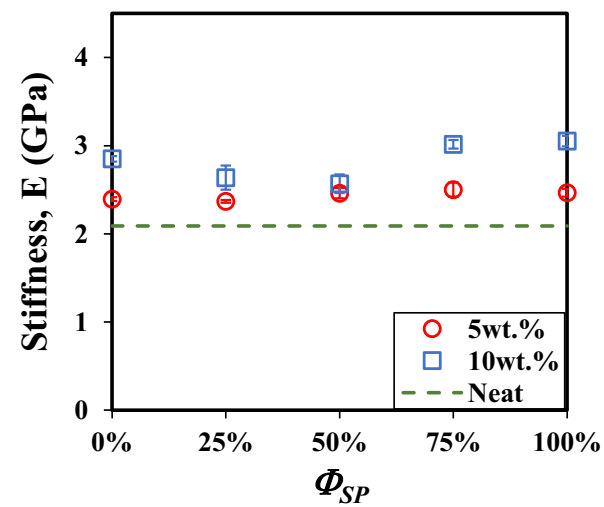

b

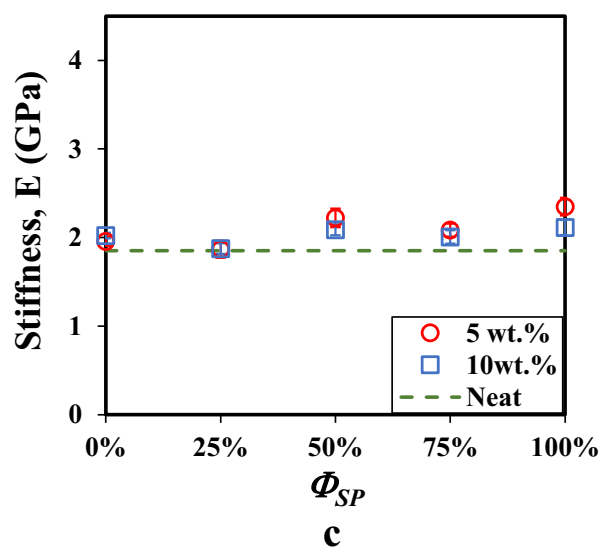

Fig. 9 Stiffness dependence. $\mathbf{a} T=15^{\circ} \mathrm{C}, \mathbf{b} \mathrm{T}=40^{\circ} \mathrm{C}, \mathbf{c} \mathrm{T}=50^{\circ} \mathrm{C}$

The distortion also accumulated in the calculation of strain energy resulted in large deviations on the estimated stress transmissibility and loss energy performance (Figs. 10, 11). Due to smaller mean value of the loss energy compared to the dynamic stiffness, the deviations in the estimated loss energy were seen larger. However, such deviations do not significantly influence the interpretation of the measured data. 


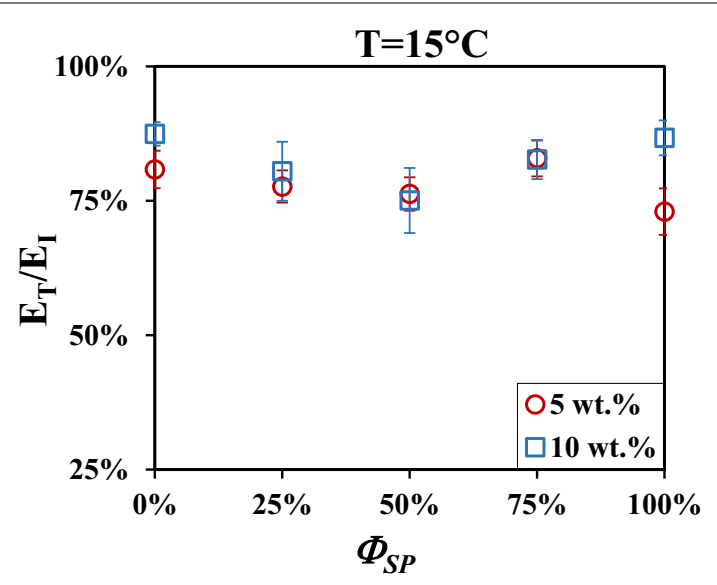

Fig. 10 Stress transmissibility dependence

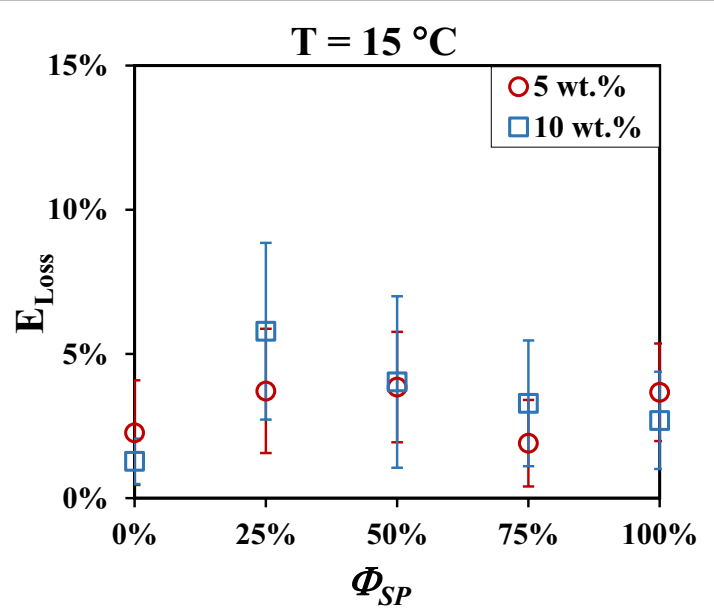

Fig. 11 Energy-loss dependence

\section{Effects of silica weight fraction}

Ma et al. [18] investigated the influence of pure nano silica particle on the dynamic stiffness of epoxy. They have reported that the dynamic stiffness increased with the weight fraction of silica particles. In the present work, mixed micro and nano silica particles were used to reinforce the epoxy adhesive. The epoxy dynamic stiffness increased with silica weight fraction regardless the size and the composition ratio of silica particles (Fig. 9a, b). Higher silica weight fraction enlarged the interface area and produced more restriction on the deformation of the epoxy matrix; thus, increased the stiffness.

The difference of the stiffening performance between silica of 5 and $10 \mathrm{wt} \%$ was obvious at $\mathrm{T}=15^{\circ} \mathrm{C}$ (Fig. 9a). However, Fig. 9b indicated that the difference became smaller at $\mathrm{T}=40{ }^{\circ} \mathrm{C}$. The stiffening performance had no significant difference at $\mathrm{T}=50{ }^{\circ} \mathrm{C}$ (Fig. 9c). Such degradation on the stiffening effect suggested a dominant effect of softened epoxy matrix caused by temperature increase [16, 21]. However, the dynamic stiffness of epoxy filled with $10 \mathrm{wt} \%$ of pure (100\%) nano silica particles always higher than 
that of the neat epoxy regardless of such softening effect. Such stiffening effect indicated the superiority of nano silica particles to restrict deformation of the softened epoxy matrix at the interface area. The increase of nano silica content to $10 \mathrm{wt} \%$ enlarged the interface area and resulted in more restriction on the epoxy matrix; thus, resulted in stiffer epoxy/silica.

The stress transmissibility increased with silica weight fraction at $\mathrm{T}=15^{\circ} \mathrm{C}$ (Fig. 10). Higher silica weight fraction provided larger interface area. Strong adhesion at the interface area facilitated greater load transfer and thus, increased the stress transmissibility. However, the load transfer ability of two sizes silica particles was lower compared to that of single size. It is believed that the reduced load transfer between silica particles and the epoxy matrix was caused by micro silica particle debonding which will be explained in the following sub-section.

The energy absorption increased with the weight fraction regardless the composition ratio of silica particles (Fig. 11). Neat epoxy exhibited low energy absorption due to its brittle nature during high strain rate loading. Cracks grew easily and resulted in a fracture to such neat epoxy [22]. The energy absorption increased as silica particles introduced to the neat epoxy [23]. Deflected crack growth due to the presence of silica particles increased the energy absorption in the epoxy/silica composite. Therefore, introducing higher silica weight fraction increased the energy absorption of epoxy/silica composite.

\section{Effects of silica micro and nanoparticle composition ratio}

Dittanet and Pearson [12] found a low dependency of the epoxy stiffness on the composition ratio of mixed micro and nano silica particles subjected to static loading. They have reported that nano silica weakened the bonding between micro silica and epoxy matrix. In the present work, a larger size ratio of micro and nano silica particle was used at high strain loading. Similar weakening effect on the dynamic stiffness and stress transmissibility was observed for the epoxy filled with two sizes of silica particles at $\mathrm{T}=15^{\circ} \mathrm{C}$ (Figs. 9a, 10). However, compared to the previous results obtained by Dittanet and Pearson [12] a higher dependency of the epoxy dynamic stiffness and stress transmissibility on the silica composition ratio was found in the present work. The composition ratio of mixed micro and nano silica $\Phi_{S P}=50 \%$ resulted in the minimum dynamic stiffness and stress transmissibility. Nevertheless, the effect of silica composition ratio on the dynamic stiffness became less significant as the temperature approached $T_{g}$ (Fig. $9 \mathrm{~b}$ for low weight fraction, and Fig. 9c for all weight fractions).

In contrast, the loss energy performance of the epoxy filled with two sizes silica was higher compared to that filled with pure micro or nano silica particles. Loss energy performance also displayed significant dependency on the composition ratio of mixed micro and nano silica particles. It was observed that the maximum loss energy performance was obtained at silica composition ratio $\Phi_{S P}=25 \%$. Interestingly, there was an optimum composition ratio $\left(\Phi_{S P}=25 \%\right)$ which maximized the loss energy performance while preserved high dynamic stiffness and stress transmissibility of the epoxy filled with mixed micro and nano silica particles. Therefore, it is possible to modify the dynamic performance of the epoxy for appropriate practical applications. 
The previous works of Dittanet and Pearson [12] and Wang et al. [4] were used to discuss the source of the weakening effect on the dynamic stiffness and stress transmissibility as well as the enhancement of loss energy performance. Micro silica particle debonding from the epoxy matrix was observed using SEM (scanning electron microscope). Nano silica increased local stress concentration at the micro silica interface resulted in debonding of micro silica. Consequently, voids were created due to particle debonding which reduced load transfer between micro silica particles and epoxy matrix and thus, reduced both dynamic stiffness and stress transmissibility. Stress concentration, which was caused by a large size ratio of two silica particles, induced micro cracks and its propagations that reduced the dynamic stiffness and stress transmissibility. In contrast, both voids created by debonding of micro silica particles and microcracks facilitated more energy dissipation in the epoxy matrix. However, the epoxy matrix mobility was increased as the temperature approached $T_{g}$ and thus, minimized such influences of voids and microcracks.

\title{
Conclusions
}

Effects of mixed micro and nano silica particles on the dynamic stiffness, stress transmissibility, and energy absorption of epoxy were investigated at high strain rate loading using the SHPB apparatus. It was revealed that the silica weight fraction dominantly governed the dynamic behavior of epoxy/silica at $\mathrm{T}=15^{\circ} \mathrm{C}$. In contrast, the dynamic behavior of epoxy/silica at a temperature close to $T_{g}$ mainly was affected by the epoxy matrix. The composition ratio contributed to the significant effects on the dynamic stiffness, stress transmissibility, and energy absorption performance. The existence of nano silica together with micro silica in the epoxy matrix decreased both stress transmissibility and the dynamic stiffness of the epoxy composite. However, it enhanced the energy absorption in the epoxy matrix. Moreover, it was found that the optimum composition ratio of micro and nano silica particles which maximized the energy absorption while maintained the dynamic stiffness.

\begin{abstract}
Abbreviations
$T_{g}$ : glass transition temperature; $A_{s}$ : cross-sectional area of the specimen; $A_{B}$ : cross-sectional area of the pressure bars; $L_{s}$ : length of the specimen; $\varepsilon_{i}$ : incident strain pulse; $\varepsilon_{R}$ : reflected strain pulse; $\varepsilon_{7}$ : transmitted strain pulse; $P_{1}$ : compressive load at the input-bar/specimen interface; $P_{2}$ : compressive load at the output-bar/specimen interface; $E$ : stiffness of neat epoxy; $E_{0}$ : stiffness of epoxy/silica composite; $C_{0}$ : elastic wave speed through the bars; $E_{\sigma}$ : stress transmissibility; $E_{\text {Loss: }}$ : energy absorption performance; wt $\%$ : percentage of weight; $\Phi_{S p}$ : composition ratio.
\end{abstract}

\section{Authors' contributions}

Conception and design of the study in this manuscript were contributed by $Y$ and YS. Y is responsible for acquisition and analysis/interpretation of data, and drafting the manuscript. YS is responsible for revising the manuscript critically for important intellectual content and give approval for the version of the manuscript to be published. Both authors read and approved the final manuscript.

Author details

${ }^{1}$ Graduate School of Engineering, Hiroshima University, 1-4-1 Kagamiyama, Higashi-Hiroshima-shi, Hiroshima 739-8527, Japan. ${ }^{2}$ Institute of Engineering, Hiroshima University, 1-4-1 Kagamiyama, Higashi-Hiroshima-shi, Hiroshima 739-8527, Japan.

Acknowledgements

Not applicable.

\section{Competing interests}

We declare that we have no significant competing financial, professional or personal interests that might have influenced the performance or presentation of the work described in this manuscript. 
References

1. Dittanet P, Pearson RA. Effect of silica nanoparticle size on toughening mechanisms of filled epoxy. Polymer. 2012;53(9):1890-905.

2. Zamanian M, Mortezaei M, Salehnia B, Jam JE. Fracture toughness of epoxy polymer modified with nanosilica particles: particle size effect. Eng Fract Mech. 2013;97:193-206.

3. Fu S-Y, Feng X-Q, Lauke B, Mai Y-W. Effects of particle size, particle/matrix interface adhesion and particle loading on mechanical properties of particulate-polymer composites. Compos B Eng. 2008;39(6):933-61.

4. Wang H, Bai Y, Liu S, Wu J, Wong CP. Combined effects of silica filler and its interface in epoxy resin. Acta Mater. 2002;50(17):4369-77.

5. Tsai J-L, Hsiao H, Cheng Y-L. Investigating mechanical behaviors of silica nanoparticle reinforced composites. J Compos Mater. 2010;44(4):505-24.

6. Zhang H, Tang L-C, Zhang Z, Friedrich K, Sprenger S. Fracture behaviours of in situ silica nanoparticle-filled epoxy at different temperatures. Polymer. 2008;49(17):3816-25.

7. Sprenger S. Epoxy resin composites with surface-modified silicon dioxide nanoparticles: a review. J Appl Polym Sci. 2013;130(3):1421-8.

8. Dorigato A, Dzenis Y, Pegoretti A. Filler aggregation as a reinforcement mechanism in polymer nanocomposites. Mech Mater. 2013;61:79-90.

9. Zare Y. Study of nanoparticles aggregation/agglomeration in polymer particulate nanocomposites by mechanical properties. Compos A Appl Sci Manuf. 2016;84:158-64.

10. Kwon S-C, Adachi T, Araki W, Yamaji A. Effect of composing particles of two sizes on mechanical properties of spherical silica-particulate-reinforced epoxy composites. Compos B Eng. 2008;39(4):740-6.

11. Adachi T, Araki W, Higuchi M. Mixture law including particle-size effect on fracture toughness of nano- and microspherical particle-filled composites. Acta Mech. 2010;214(1-2):61-9.

12. Dittanet P, Pearson RA. Effect of bimodal particle size distributions on the toughening mechanisms in silica nanoparticle filled epoxy resin. Polymer. 2013;54(7):1832-45.

13. Guo Y, Li Y. Quasi-static/dynamic response of $\mathrm{SiO}_{2}$-epoxy nanocomposites. Mater Sci Eng A. 2007;458(1-2):330-5.

14. Goglio L, Peroni L, Peroni M, Rossetto M. High strain-rate compression and tension behaviour of an epoxy bicomponent adhesive. Int J Adhes Adhes. 2008;28(7):329-39.

15. Naik NK, Shankar PJ, Kavala VR, Ravikumar G, Pothnis JR, Arya H. High strain rate mechanical behavior of epoxy under compressive loading: experimental and modeling studies. Mater Sci Eng A. 2011;528(3):846-54.

16. Gómez-del Río T, Rodríguez J. Compression yielding of epoxy: strain rate and temperature effect. Mater Des. 2012;35:369-73.

17. Chaudhary S, labal N, Mangla V, Kumar D, Roy PK. Strain rate sensitivity of toughened epoxy. Iran Polym J. 2015;24(10):871-81.

18. Ma P, Jiang G, LiY, Zhong W. The impact compression behaviors of silica nanoparticles_epoxy composites. J Text Sci Technol. 2015;01(01):1-11.

19. Omar MF, Akil HM, Ahmad ZA. Particle size-dependent on the static and dynamic compression properties of polypropylene/silica composites. Mater Des. 2013;45:539-47.

20. Tian Y, et al. High strain rate compression of epoxy based nanocomposites. Compos A Appl Sci Manuf. 2016:90:62-70.

21. Owens AT, Tippur HV. A tensile split Hopkinson bar for testing particulate polymer composites under elevated rates of loading. Exp Mech. 2009;49(6):799-811.

22. Kanchanomai C, Rattananon S, Soni M. Effects of loading rate on fracture behavior and mechanism of thermoset epoxy resin. Polym Test. 2005;24(7):886-92.

23. Marouf BT, Mai Y-W, Bagheri R, Pearson RA. Toughening of epoxy nanocomposites: nano and hybrid effects. Polym Rev. 2016;56(1):70-112.

\section{Submit your manuscript to a SpringerOpen ${ }^{\circ}$ journal and benefit from:}

- Convenient online submission

- Rigorous peer review

- Immediate publication on acceptance

Open access: articles freely available online

High visibility within the field

- Retaining the copyright to your article

Submit your next manuscript at $>$ springeropen.com 